\title{
Paradoxes of Property: Piracy and Sharing in Information Capitalism
}

\author{
Jonathan Paul Marshall and Francesca da Rimini
}

The concept of 'property' is inherently tangled in contradictions and disorders, especially within Information Capitalism where ideas and culture have to be restricted to make a profit, and shared in order to innovate. Marking out property as 'private' and 'profitable' means that it has to be separated from the social complex of its origin, so that this origin is both obscured and marked by the prospect of violence and theft. As David Hume and Pierre Joseph Proudhon suggest property is driven by imagination, metaphor, power, its contribution to symbolic identity, and throughout, by conflict over originality and copying. In Information Capitalism, the tools of 'knowledge' workers are the tools by which their creativity is appropriated, captured and displayed, and their access to property is acquired or retained for the uncertain future. In this situation the boundaries between property and piracy become even more ambiguous. This situation is explored through considering the social formations and activities around peer to peer file-sharing, and the court case involving The Pirate Bay, in which the roles of metaphor and the tension between property, survival and theft are clearly displayed.

\section{Introduction}

All societies both suffer and benefit from levels of what is perceived as disorder, and the guiding principles of the society may be contradictory, or paradoxical, in that their ordering systems create disorder. Our aim in this text is explore the disorders and vagaries of property that seem essential to its continuance, construction and destruction, and then demonstrate how these paradoxes play out in the information economy in particular within the domain of peer-to-peer (P2P) filesharing. We do not wish to reduce these paradoxes and contradictions to a temporary error or to a future ordered synthesis, but to take them as they are in all their splintered fury. Much contemporary social action stems from these incoherencies, and the disputes, displays of power, and innovations which circle around them. In the P2P field the disorder generated by the order of property provides opportunities for new productive and adaptive social and technical forms of life to emerge.

By contrasting order and disorder we are not implying the necessary existence of a binary distinction between the two, or that definitions of order and disorder will 
not change depending on the social position of the definers. Disorder is not always and everywhere the same. It resists definition, which adds to its effects.

\section{The Incoherence of Property}

\section{Property and Imagination}

Eighteenth century British philosopher David Hume argued that private property is both essential for social order, and imaginary.

[D]isputes may not only arise concerning the real existence of property and possession, but also concerning their extent; and these disputes are often susceptible of no decision, or can be decided by no other faculty than the imagination (1888: 507).

Hume argues that property and its boundaries are constructed via metaphors which do not so much reflect 'reality' as they express the properties of the mind and social habit, and this causes problems with drawing ownership boundaries around property.

He illustrates this by a story of two Grecian colonies who heard of an abandoned city. Arriving at the same time, their official messengers began a race and, as one was slower than the other, he:

launch'd his spear at the gates of the city, and was so fortunate as to fix it there before the arrival of his companion. This produc'd a dispute betwixt the two colonies, which of them was the proprietor of the empty city; and this dispute still subsists among philosophers (1888: 507-8).

The dispute is impossible to settle rationally because it depends upon claims made to the imagination about the attachment of the messengers to their cities, whether the race was to the gates or the wall, whether the spear forms better or equal contact to the hand, and whether, if the spear had not held, the claim would still count.

For Hume, property is built from metaphor; it becomes a concretising rhetoric in action. There is no a priori to property, any example can be disputed, even though property is vital for social order.

More conventionally, John Stuart Mill held that what a person owns as property depends on their own labour: 'The foundation of the whole is the right of producers to what they themselves have produced' (Mill 1909: 218). This implies that unequal distributions of property come about either because of a just agreement, or because 
people give up the products of their labour, in exchange for survival. Mill recognises difficulties with his formulation, as he acknowledged the existence of appropriation and the difficulties of drawing a boundary line around people's collaborative labour, but he largely put these difficulties aside (ibid: 219ff). Further complications arise when different groups differ about what activities and types of labour are valuable, and thus have different imaginings of the 'just' distribution of property. Property becomes political, and a matter of relative power. Disputes over imaginings may end up being resolved by force. As Adam Smith wrote:

Civil government, so far as it is instituted for the security of property, is in reality instituted for the defence of the rich against the poor, or of those who have some property against those who have none at all (1979 II: 715).

Nineteenth century anarchist Pierre Joseph Proudhon pointed out that property is intrinsically theft (nd: $37 \mathrm{ff}$.); not only because property is often appropriated from others by force, but also because something becomes property only if someone else can steal it. Property and theft give birth to each other. We can here instance the Marxist argument that capitalist systems of property were indirectly promoted when English aristocrats dispossessed peasants of their traditional land and commons, thieving it to make parks or to grow wool, and forcing a newly-pauperised class into the cities where they became cheap wage labour (Linebaugh \& Rediker 2000). Through use of enclosure, aristocrats eventually undermined the feudal relationship with the peasantry, which was the basis of their power (Federici 2004).

Another example, this time unsuccessful, of how property/theft works through the appropriation of 'common rights', occurred when Bechtel Corporation in Bolivia, backed by the World Bank, attempted to criminalise the capture of rainwater by alleging that all water was its private property. Its claims were eventually abandoned due to public protest (Chatterjee 2003; ENS 2006). Similar laws exist in the US state of Colorado, where almost all water, even rain, is 'owned' by people who have bought rights to the waterways (Ingold 2009). Hence, '[p]reventing that water from reaching a river — and thus, its rights holder — is akin to stealing' (ibid.).

'If you try to collect rainwater, well, that water really belongs to someone else,' said Doug Kemper, executive director of the Colorado Water Congress. 'We get into a very detailed accounting on every little drop' (Riccardi 2009). 
Similarly, in 1995, the US Congress turned the resource of unused broadcasting frequencies into property, giving those frequencies to media corporations free of charge in perpetuity, thus initiating what Republican politician Bob Dole called 'a giant corporate welfare program' (Barnes 2006: 19).

Cultural expression is also increasingly bounded. Before 1976, US copyright could last for a maximum of 56 years. The Act of 1976 extended that to the life of the author plus 50 years. An Act of 1998 extended that to life plus 70 years, or 75 years in total for 'corporate authorship'. The US Congress's 'multibillion dollar allocation decision... ensured that virtually no creative works would enter the public domain over the following two decades' (Tehranian 2007: 540). More recently, the United States government (in alliance with the entertainment industry) attempted to 'bully' Spain into adopting extreme anti-piracy measures, as part of a project of 'harmonisation' which 'continuously ratchet[s] up copyright protection, one country at a time' (Hinze 2010; Anderson 2010). 'Property' held in common is being reduced, sometimes by stealth, supporting Adam Smith's already mentioned claim that government exists to extend the reach of the property claims of those who already have.

\section{'Normal Exchange'}

A more anthropological way of conceiving property, connects property to what we will call 'normal exchange' ${ }^{1}$. In this view humans, throughout their existence as a species, have primarily lived in hunter-gatherer, or slash and burn agricultural societies, where massively inequitable accumulation is rendered socially unlikely by mechanisms that prevent people from accumulating too much status or property. Property implies obligation. If your kin demand property off you, and you refuse, then you will be ostracised as a 'thief' - a person who does not acknowledge others. As well, in these societies, most goods rot and thus cannot be accumulated. If goods rot slowly, then accumulation is limited by what can be carried. Hence a limit to accumulation arises, and it becomes strategically better to give goods away to make, or reinforce, relationships and culture, and to build obligation, status or self-identity. As a result, property is nearly always in circulation. While these societies may have hierarchy (especially a gender and age hierarchy), what members can take or have at

\footnotetext{
${ }^{1}$ The writing on 'traditional' economics and its politics is enormous. General texts include: Mauss 1997; Sahlins 1974; Clastres 1989; Wilk \& Cligget 2007.
} 
the expense of others is limited, whilst in more hierarchical societies some people can violate this balance and accumulate property, without yielding it on demand, or giving it away in exchange and feasting. If we note Proudhon's paradox that what enables society might also destroy it, and that the harm and abuse resulting from property cannot be dissevered from the good, this accumulation might be positive, as it allows people some independence from the group. Yet this anthropological view implies that we can expect that attempts to extend individual or corporate property at the expense of others, or at the expense of cultural expression, will meet resistance, and the hierarchical boundaries between theft and property will be contested.

To summarise: Property is imagined, and arises out of a social-historical network of co-production, creation, distribution, conception and relations of power. It is difficult to extract bordered property from this network and impossible to give it a single cause without an act of socially-legitimated 'theft', backed by some others, which extracts it from its messy origins. Property has no eternal essence and no boundaries: it is a network, or process, involving the whole of social action. Things are constantly becoming-property and escaping being property, amidst conflict and decay. As Proudhon claims, 'property is impossible' (nd: 157ff).

\section{Property, Copying and Culture}

\section{Property and Identity}

Because property is so implicated in the imagination it can become a way that we imagine ourselves and our potencies ${ }^{2}$. We use property, words and ideas as tools to express ourselves and participate in social life. Property can give the rewards of, or help establish, class and status, which is why theft or loss might be so powerful; loss can represent a diminishment of personal existence. In some societies there may be no 'you' outside of the display or exchange of property. Renunciation is not commonly available in information capitalism as, within its framework, it is primarily newlyowned 'things' that promise fulfilment in a never-ending cycle of desire, display and consumption.

The role of property in constituting identity in information capitalism leads the consumer to conflicts. On the one hand, mass consumption provides something to share and discuss; experiences and items in common with others, in what may otherwise be a fractured life. However, in so doing, it also renders you the same as

\footnotetext{
${ }^{2}$ Basic writings on this subject include: Douglas 1996; Bourdieu 1985; Bauman 2007.
} 
everyone else and thus undermines your valued 'individuality'. In this set up, there is always the need for recognised distinction, although this does not include the distinction which arises from not having property; that is simply recognised as failure.

When others buy or take the almost identical property, then you are threatened as they are effectively stealing your distinction and hence your 'identity'. This can lead to a spiral of ever more intently keeping up with the new, and thus taking the risk of embracing something which does not become recognised, which is just 'trash'. In that sense, identity becomes fashion, and people will try and embrace the latest as soon as it arrives and has a reasonable chance of being accepted and, like other forms of acquiring and producing culture, this often involves copying. Copying may be hindered if brand names (of clothing, cosmetics, hi-tech gadgets, etc) become a mark of authenticity or wealth or adequacy. However, in some groups the ability to thieve, or rip off, the latest, may be taken as evidence of identity factors of skill, status or having high-tech marketability. Even so, the thief, pirate, or counterfeiter will have to risk delaying long enough for it to be recognisable that he or she got it first; too soon and it's worth nothing.

Copying and transformation are vital to imagination and hence property. Without copying there is no potential transformation, and no combining images and ideas into new images and ideas. As philosopher and religious scholar Rene Girard says: 'there is nothing, or next to nothing, in human behaviour that is not learned, and all learning is based on imitation. If human beings suddenly ceased imitating, all forms of culture would vanish' (1987: 7). Girard argues that imitation is ambivalent as, while we learn through emulation, if two people reach for the same thing, or the student supersedes the teacher, conflict easily arises. Consequently societies tend to be ambivalent about imitation, recognising also that it is a source of magical attack and vulnerability, as with the 'voodoo doll'. Modern Western societies tend to officially regard over-zealous imitation as bad, with originality marking creativity, but it has not always been so.

\section{Ambiguity and Poetics of Theft}

Even under hierarchy we can point to ambivalences about theft. Some thieving becomes the basis of legally legitimate property, but there can also be sympathy when someone steals to feed their family, or when a Robin Hood type hero takes from those who have more than they need or who deprive others. In fairy stories, stealing from a 
giant is particularly acceptable, perhaps because folk tales originate with people facing their giant masters. Hence, the 'good thief' is an archetype we cannot ignore, however much it aggravates those with property.

What counts as bad piracy depends on the current politics. Pirates like Francis Drake and Walter Raleigh were much praised in England. They received State sponsorship in reaction to the Spanish theft of gold and silver from South America; and the pirated gold was more productively used in Britain than in Spain. Piracy was an important part of the American Revolution, promoting attacks on the Royal Navy by melding patriotism with commercial gain (Patton 2008). After Independence the US thrived on pirated goods and intellectual property (Ben-Atar 2004); there was no protection given to the books of foreigners manufactured outside the US until 1986 (Choate 2005: 41). Hollywood was founded in an attempt to escape Edison's patents by shifting to the other side of the continent (Lessig 2005: 53-4). Today, rising powers such as China also maintain a lax attitude to protecting foreigners' IP for the sake of their own economic development. The imaginings used to establish boundaries between property and theft are disputed and depend on relations of power and capability. Nevertheless, we should not forget that many pirates have gained profit out of murder, terror and slavery.

There is, then, a piracy of the relatively weak and of the relatively strong. Piracy of the relatively weak occurs when markets are restricted, or the equity of 'normal exchange' is violated; whether by 'corrupt' class structures, or through what appears to be artificial restriction of goods. Such piracy is often a reaction to perceived illegitimate and excessive profits, or occurs when people revert to hunter-gatherer modes of exchange and control, seizing back property they do not believe belongs exclusively to another. Piracy further occurs when the labour and risk involved in theft are minimal in comparison to the profit or enhanced opportunities.

Piracy is ambiguous, and imagining file-sharing as 'piracy,' and situating it within an exciting and sometimes approved good-thief activity, might have diminished the legitimacy of corporate prosecution. Nowadays, corporations tend to metaphorise file-sharing as a 'criminal' activity hurting not only admired 'celebrity stars' but also the economy, while file-sharers still use the metaphor of 'pirate' as with The Pirate Bay and the various parliamentary pirate parties.

\section{Intellectual Property in the Information Society.}


As we have argued, copying, sharing, transforming, elaborating, commenting, building and innovation are embedded within cultural production. Sociologist Maurizio Lazzarato (1996: np, italics in original) argues that in the information society commodity property is constituted 'in forms that are immediately collective,' existing 'only in the form of networks and flows'. Furthermore the foundations of this property is blurred as:

the activity that produces the 'cultural content' of the commodity... involves activities... not normally recognized as 'work' [such as] defining and fixing cultural and artistic standards, fashions, tastes, consumer norms, and, more strategically, public opinion (ibid.).

Similarly Rasmus Fleischer (musician and founder of the Swedish anticopyright think tank Piratbyrån) and Palle Torsson (artist and Piratbyrån associate) argue, sharing 'is not optional but inscribed in the technique we use every day' (Fleischer \& Torsson 2005).

However, while information capitalism demands free circulation of information to allow the production of 'new' ideas and cultural works, it simultaneously must stop ideas from circulating freely so as to profit from them. This produces incoherency. The more ideas are copyrighted, the less a person can imagine freely without trespassing on another's property rights. Paradoxically for example, by putting a financial cost on sampling in music, fewer samples can be used in a new song, making it more derivative of its sources and thus less original.

Culture has become restricted by property rights, while at the same time, the skills and tools necessary for successful information/cultural labour are not confined to the working day, as in industrial capitalism, but spill out into cultural and personal life in general. Retaining familiarity with current culture can be vital for a worker's employment, future creativity and social self-identity. Similarly, capitalists gridlocked by patents (cf. Heller 2008), might even welcome sharing if they were not dependent upon such enclosures and boundaries for profit.

P2P file-sharing systems illustrate the ambiguities of sharing, theft and cultural value (as appropriation, identity and creativity) in information society. Although it is often treated as piratical, file-sharing can be a legitimate gifting of public domain material or of a person's own work. This 'normal exchange' was the way ideas leading to the construction of the internet were developed, and led Tim Berners-Lee to develop and gift HTML and the graphical interface system of the World Wide Web to 
the world (Berners-Lee 1999). It is part of what made the early Web so attractive to non-specialist users. However, almost from its outset some wanted to 'commercialise the internet', and make it corporate rather than common property, eventually spawning the 'venture capitalist's paradise' of Web 2.0 in which mass users provide the creative labour and content which has generated stratospheric profits for an elite in a piracy of the strong (Kleiner 2010:15). While users might provide the property voluntarily, it is doubtful that they have formally given permission for profit to be seized from their labour or even comprehended that their labour is being monetised for the benefit of others.

In general, files available via P2P sites are usually 'cultural products' which are owned by content industry bodies who have either financed their production or been assigned the copyrights. Comments on P2P forums reveal that many P2P users dispute the legal and social assumption that content owners have greater rights than either the original (often exploited) creators or those who desire to participate freely in cultural exchange. This 'injustice' is partially remedied by 'piracy'.

Information piracy is also tied to modes of consumption, becoming easier with the high bandwidth that enables online gaming, video streaming, and legitimate downloads. Thus piracy is caught up in the very process of providing new ways for people to consume. Internet Service Providers (ISPs) may find file-sharing a profitable driver of the generous download plans they offer customers. Attempting to prevent piracy cuts into their own profits in order to defend someone else's. Hence many ISPs resist the attempts of the Media businesses to use the State to enforce media favourable ownership rules, to constrain the activities of their customers, sometimes proposing solutions to the 'problem' that allow them to carry on business as usual (see, for example, iiNet 2011; Lasar 2011).

\section{Peer-to-peer (P2P): Property, Culture, Metaphor and Control P2P}

$\mathrm{P} 2 \mathrm{P}$ refers to the suite of software programs, protocols and social practices that enable this form of online digital exchange. The P2P phenomenon depends on 'normal exchange'; free software conventions, volunteer labour and a collective desire for access to cultural materials unfettered by hardware and software locks, copyright restrictions and other forms of enclosure. 
P2P also disrupts itself in many ways. Instead of a 'network society' P2P fosters a 'swarm society' with some unusual features and vulnerabilities. Swarms form temporarily and disintegrate without forming ongoing networks, and people cultivate anonymity. Members display they are there, but do not know on whom they depend. Contact is contingent on the exchange, but may become more stable in the forums attached to particular sites.

As a result, file-sharing seems affected by the 'tragedy of the commons' argument, that free systems collapse because some people take advantage of them when the means of social control is not strong enough to prevent this. People might take files but not make them available, because they have inadequate storage space, bandwidth, or interest. Such people may be scorned, but the relationships are not strong enough to alter behaviour, although many semi-private and private sites insist upon fair download/upload ratios and suspend privileges of non-compliant members. Nevertheless, the majority of file-sharers use public trackers with no such controls, and therefore sociality among $\mathrm{P} 2 \mathrm{P}$ participants tends to be relatively weak, and liable to fracture.

Such conflict and incoherence is also implied by Cox, Collins and Drinkwater's (2010) study comparing the attitudes of Finnish file-sharers who uploaded original copies of files ('first-seeders') with those who either downloaded them and continued to seed ('seeders'), and those who did not reseed ('leechers'). They discovered that leechers were much more likely to believe that 'legal blame' should fall exclusively 'upon the shoulders of seeders'. In contrast, first-seeders and seeders believed that 'no individual or group should be legally liable for file-sharing activity'. As leeching would be impossible without the labour and risks undertaken by first-seeders, it may seem surprising that 'leechers' would be so harsh on them, yet this common attitude evidences the fractured ties amongst members of ephemeral swarms.

$\mathrm{P} 2 \mathrm{P}$ is also parasitic on other systems for its survival and the survival of its users. As Andersson (2006) writes, this peer labour 'is dependent on already established prosperity; it is a form of "free" labour which one can afford, given that one has got the required material setup as well as the time, skill, and intellectual capacities'. P2P may also undermine the payment of those who use it to produce culture, by making their, or other, work available for free, thus undermining users' prosperity and ability to participate. 
P2P has also birthed a burgeoning field of 'anti-piracy enterprise', as Ramon Lobato and Julian Thomas (2011: 4) point out. These enterprises are diverse, including developers of Digital Rights Management (DRM) technologies like Audible Magic, internet traffic analysis firms like Sandvine, and cease-and-desist notice senders MediaSentry and DtecNet (ibid. 8, 10, 13). These organisations all ostensibly seek to 'prevent, measure, transform, and otherwise derive revenue from copyright infringement' (ibid. 4). However, as their business models depend upon the continuance of piracy, total prevention would equate with their commercial failure. This leads to ongoing manufacture of alarm, diversification of their client base and development of technologies which 'monetize, rather than merely obstruct, infringement', a method followed by both Google and YouTube (ibid. 10).

P2P also faces problems around the failure of indexing, and ongoing sabotage via promulgation of broken files or the insertion of viruses into files. Companies such as Anti-Piracy LLC, Overpeer, Nuke Pirates, C-Right, and Media Defender specialise in such digital 'spoofing' and 'spoiling', aiming to drive 'would-be pirates' to legal services (Lobato \& Thomas 2011: 9). As a result, irritation, disruption and paranoia become a magnified part of swarm sociality.

Sometimes file-sharing platforms vanish due to legal challenges arising because the software is too attractive - as was the case with the early centralised file-sharing system Napster. However, Napster's legal (and later commercial) failure encouraged further inventiveness by hackers and users. In this case leading to the development of the BitTorrent protocol enabling fully-distributed file-sharing systems which share bandwidth and file chunks amongst a network of participants, none of whom know which chunks they are transmitting at any one moment (Bridy 2011). These files are linked by indices (or 'torrents') stored on computer servers such as the Swedish initiative The Pirate Bay (TPB).

Significantly, TPB does not store any of the artefact data, only the metadata (keys) to locate it elsewhere. ${ }^{3}$ As each peer receives a packet of data onto their own computer, this data is available to be automatically seeded to any other peer connected

\footnotetext{
${ }^{3}$ In February 2012 TPB shifted from indexing torrents to providing 'magnet' links, a system which provides users with a 'decentralized way' of requesting a file rather than using a 'centralized torrent server to connect the user with another peer' (Geuss 2012). The shift was made for 'survival' reasons, as the smaller magnet files significantly reduce server space, allowing 'copies of The Pirate Bay site' to be made more easily should anti-piracy laws shut it down without warning.
} 
to the same swarm; in effect downloaders must become uploaders to continue the exchange, at least until they have acquired a complete copy of the file.

Nevertheless, far from retreating from disputes over property by claiming innocent neutrality TPB has taken a 'strategic' position in the global 'copyfight' (Andersson 2009). The 'politicisation' of file-sharing in Sweden, as exemplified by people's participation in the advocacy organisation Piratbyrain and the political party Piratpartiet, has been directly attributed to the criminalisation of the activity by the media industry. Under this pressure, the Swedish 'cyberpirate' metamorphosed into a 'political partisan', and their discourse expanded from that of 'law and copyright', to broader questions of 'politics and participatory culture' (Dahlberg 2011: 273).

\section{The Pirate Bay}

The Pirate Bay (TPB) was launched in November 2003. In 2008 The Pirate Bay's four founders were charged with copyright infringement offences. The ensuing trial found them guilty, and imposed punitive fines (of about US\$3.6 million) and a year's jail time for each. On appeal, jail terms were reduced but the fines increased. Three of the defendants subsequently signalled their intention to appeal to the Supreme Court, and in October 2011 Sweden's Prosecutor General recommended that this final appeal be denied because problems in The Pirate Bay case were 'so complex' the country's highest court 'might not be the appropriate venue to tackle them' (enigmax 2011); an unusual argument about the capacity of the courts. The case concluded on 1 February 2012 when the Supreme Court refused to hear the appeal motion, and consequently the founders'existing jail sentences and fines are final (Anderson 2012). However, this outcome does not appear to affect the site's capacity to continue operating as normal, as according to its blog it moved to the .SE domain, thereby giving some breathing space from the legal reach of the 'United States of Arrogance' (The Pirate Bay 2012). Moreover, it appears that TPB was sold some years earlier (in mysterious circumstances), and so is no longer under the control of the founders (Anderson 2009).

Meanwhile TPB continues to flourish as the world's largest public torrent tracker. According to the statistics on the site's front page in December 2011, TPB hosts ' 32.119 .444 peers (22.961.788 seeders +9.157 .656 leechers) in 4.053.530 torrents' (The Pirate Bay 2011b). It was also ranked as the $86^{\text {th }}$ most popular website in the world by Alexa Internet (2011) in mid-August 2011. 
TPB has close ties to the Piratpartiet (Pirate Party), a political party which arose in late 2005 from the public support given a petition protesting against a proposed change in Swedish copyright laws which would criminalise downloading (Miegel and Olsson 2008: 208-9). The party's announced core vision is 'Shared culture,' 'Free knowledge' and 'Protection of privacy', aims that have been broadly mirrored by pirate parties formed elsewhere. It claims that:

Terrorists may attack the open society, but only governments can abolish it. The Pirate Party wants to prevent that from happening... The official aim of the copyright system has always been to find a balance in order to promote culture being created and spread. Today that balance has been completely lost, to a point where the copyright laws severely restrict the very thing they are supposed to promote. The Pirate Party wants to restore the balance in the copyright legislation. All non-commercial copying and use should be completely free. File sharing and $p 2 p$ networking should be encouraged rather than criminalized. Culture and knowledge are good things, that increase in value the more they are shared (Piratpartiet nd1). The party is thus in favour of 'normal cultural exchange' as defined earlier.

In 2009 the Piratpartiet won two seats in the EU parliament (Schofield 2009). This signalled that the contest over knowledge and property was no longer a fringe matter, nor a subject to be framed only by corporate financial interests. Piratpartiet's precedent-setting success, not only in the European Parliament but in the wider sphere of public discourse, is in part due to the party's deep interconnections with other localised 'strategic, politicised entities' such as the 'propaganda institute, think-tank and alternative news agency' Piratbyrån (the Pirate Bureau) and TPB (Andersson 2010: 196). TPB itself was founded by Piratbyrån but soon claimed autonomy.

As well as restricting circulation of ideas, copyright can also be used to suppress discussion about property. One company not only threatened The Pirate Bay for violating the copyright of their clients but also threatened the TPB with copyright suits if they made the contents of that threatening email public (Jgela1 2005). Undeterred, TPB continued to publish a cache of such documents, and their own replies, on their website, declaring that ' 0 torrents has been removed, and 0 torrents will ever be removed' (The Pirate Bay 2011a). A TPB response to Dreamworks in 2004 is typical of their approach. 
As you may or may not be aware, Sweden is not a state in the United States of America. Sweden is a country in northern Europe. Unless you figured it out by now, US law does not apply here. For your information, no Swedish law is being violated.... It is the opinion of us and our lawyers that you are morons, and that you should please go sodomize yourself with retractable batons (ibid.)

Such 'caustic, sarcastic' letters might even help convince the court that TPB demonstrated enough 'subjective intent' to be held liable for copyright infringement (Carrier 2010: 12), again foregrounding the role of imagination in the construction of property and theft.

During the course of The Pirate Bay trial, metaphors were used to define and bound property. The core defence argument was that The Pirate Bay was a search engine like Google and thus subject to the same protections as Google. Defence lawyers claimed that in providing a service, which could be used both legally and illegally, TPB was not breaking the law, any more than manufacturers of cars which could break speed limits were breaking the law. They referred to 'safe harbour' protections entrenched in laws around the world, arguing that:

EU directive 2000/31/EC says that he who provides an information service is not responsible for the information that is being transferred. In order to be responsible, the service provider must initiate the transfer. But the admins of The Pirate Bay don't initiate transfers. It's the users that do and they are physically identifiable people. They call themselves names like King Kong... According to legal procedure, the accusations must be against an individual and there must be a close tie between the perpetrators of a crime and those who are assisting (enigmax 2009).

The prosecution argued that The Pirate Bay assisted the commission of a crime and that, according to Sweden's Supreme Court, a person holding the jacket of someone committing battery can be held responsible for the battery. It was alleged that The Pirate Bay was gaining income from criminal activities via advertising and that it was negatively affecting industry. The court rejected the defence's argument saying that the defendants knew the site was being used for illegal activities and they did nothing to prevent it; they were found to be accessories, to a crime that was not proven (Lewan 2009). As said previously, both sides appealed the result. 
As Hume implies, whether we accept the argument of prosecution or defence depends to a large extent on pre-existing alliance or on whether we are prepared to accept the metaphors describing The Pirate Bay as an innocent search engine, as a mugger, or as holding the coat of a mugger.

Other metaphors came into play. Malin Littorin-Ferm, organiser of pro-Pirate Bay protests said 'we young people have a whole platform on the Internet, where we have all our social contacts - it is there that we live. The state is trying to control the Internet and, by extension, our private lives' (UPI 2009). This if anything shows the ways that private and public have changed and how that affects contests over property. The argument of the protesters again depends upon us seeing people's activities at The Pirate Bay as a routine and essential part of social-cultural life. From a different everyday perspective, Paul McCartney, whose music returned over 300 results on a recent TPB search, said 'If you get on a bus you've got to pay. And I think it's fair, you should pay your ticket' (McKenzie \& Cochrane 2009). His metaphor 'forgets' that some places do have free buses.

The vagueness of boundaries of violation arose when one of the prosecuting organisations demanded that ISPs not connect to The Pirate Bay. A lawyer for Telia Sonara, a communications company, said:

In part, this is not a legally binding decision, but above all, this is a judgement against Pirate Bay and nothing that effects any service provider. We will not take any action (to block) the contents if we are not compelled to do so.

And the managing director of another company said 'We will not censor sites for our customers; that is not our job' (TT 2009).

Debates over the correct imagining of intellectual property continued on public websites. This is not just a matter for academics, lawyers or copyright holders, it is an imagining or seeking of metaphors that goes wherever people are concerned about property relations and the foundations can never be settled. Rather than seeing these a logical arguments, let us see them instead as metaphors of property and understand how unstable property imaginings are. Significantly, in spite of the rapidly shifting technological, legal, and social circumstances enveloping file-sharing, the range of metaphors remains relatively stable over time. One person wrote:

This is like prosecuting the postal service, there is a great deal of criminal activity via the post, however are they on trial here? they are a medium of 
communication nothing else, it is not up to the Post Office nor service providers to police IPR [intellectual property rights] infringements!

Others complained that industry was not taking advantage of the new technology and the court's decision was (metaphorically) like legislating to preserve steam trains at the expense of other transport. Another compared P2P to walking into your local supermarket and shoplifting DVDs. Others objected to this metaphor because of the difference between scarce and infinite resources, or because if a friend gave you a copy of a DVD almost nobody would think that was theft. One person wondered if movies should be able to make as much money as they sometimes do in a world with real poverty. In response another said that pirating could destroy small film producers, who made almost no money (Comments on TT 2009). Others argued that while the cost of manufacture of CDs had decreased the price had not, so corporations thieved from the public, and that $\mathrm{P} 2 \mathrm{P}$ was like listening to a radio station (Comments on Landes 2009a). Others continued arguments that the corporations were supporting dead technology, that:

The major labels could have charged for P2P transfers for the last decade. Instead, they demonised the technology, tried to bully their customers unsuccessfully and left all that money on the table. But that ship has sailed.

The losses corporations were claiming from piracy were compared to speculation or fortune-telling, and it was alleged that mainstream companies destroyed local cultural production and thus should receive no sympathy (Comments on Landes 2009b). This diversity of metaphor also displays the ways that property becomes a mode of comparison, rather than a thing in itself.

\section{Failed Control}

Industry-commissioned P2P traffic figures show that attempts to curb mass filesharing by bringing civil and criminal actions against entities and users have failed. The Technical report: an Estimate of Infringing Use of the Internet by anticounterfeiting and piracy company Envisional estimated that $23.76 \%$ of global internet traffic was 'infringing' (2011: 2). Moreover, it estimated that BitTorrent (BT) traffic accounted for $17.9 \%$ of all internet traffic, two-thirds of which was deemed to be 'non-pornographic copyrighted content shared illegitimately' (ibid.). At any time 
over 8 million people could be exchanging files using the BT protocol, out of a pool of 100 million regular users worldwide (ibid. 4).

If these figures are more or less accurate then social norms are not changing in response to legal action and spectacular trials, demonstrating Hume's proposition that property belongs to the realm of the imagination. Millions of otherwise relatively lawabiding people are regularly downloading cultural content, implying that they do not imagine their acts as criminal, or reasonably disapproved of. Instead, they imagine cultural artefacts as the property of no-one, or of everyone, as in 'normal exchange'. Moreover, the experience of being in a swarm, especially one associated with a widely used public tracker such as TPB, can assuage an individual's apprehensiveness about personal risk. As regular TorrentFreak commenter Violator0 (ernesto 2011) noted, 'Like wildebeest crossing the river only a few will be taken down and eaten by the crocodiles. Doing the same in small groups leads to a much higher percentage of death so the larger your swarm the better'.

Faced with this disobedient multitude, and difficulties with different laws in different countries, powerful industry/State alliances have attempted to preserve and extend capitalist profit and property by intensifying copyright legislation in national jurisdictions around the world, developing multilateral treaties to expand copyrights and decrease fair and previously normal usages. This is an example of 'piracy of the strong'. Signatories to the most powerful of these treaties, the Anti-Counterfeiting Trade Agreement (ACTA), must agree to change existing sovereign law to comply with ACTA's 'harmonisation' goals. Although ACTA's early drafts were kept private, leaks inevitably occurred. Consequently the final draft was considerably watered down due to highly organised lobbying by groups such as La Quadrature du Net (2010) and Knowledge Ecology International (2011), and the growing involvement of political pirate parties. Responding to the transnational piracy of the strong we have a transnational 'piracy of the weak' who combine their understanding of contemporary social desires and cultural mores with cooperative, agile use of networks, metaphor and creative expressions to fight what they deem to be corporate theft. Organisation provokes counter-organisation to disorder it, and vice versa.

Even when passed, attempts to create obedient consumers are unstable. For instance, Hadopi, the French government agency charged with administering the country's anti-file-sharing laws, is struggling with the sheer amount of digital property 'crime'. In July 2011 it reported it was unable to keep up with the 8 million 
complaints it had received from the internet security company MediaSentry; processing only 470,000 initial warning e-mails, 20,000 second notices, and 10 thirdstrike notifications which require a judge to approve a temporary internet suspension and/or fine (Lee 2011). Enforcement is being overwhelmed by the theft the new legislation manufactures.

\section{Conclusion}

Although property can form, or contribute, a basis for social order it has no logical or inevitable basis in itself. We have suggested that throughout most of human evolution, property has been circulated not accumulated; existing so as to build relationships, be consumed, gain status and make culture. Class structures arise when these 'normal' human modes of exchange are circumvented. Accumulated 'private' property, although bringing some security, potentially clashes with 'normal exchange' and is a product of a history of appropriation and competing imaginings; it emerges out of a web of relationships and prior production, appropriation and distribution, and it. As a result, property ownership always has boundary problems, and extracting it from this web becomes political; a matter of imaginal representation, metaphor, rhetoric, and the use of power. Theft is itself ambivalent, with the common idea of the good thief, taking property from those who either do not need it or who are unworthy of it. The 'good' pirate can also be part of a means of prosperity recognised by the State. In this chapter we distinguished between the piracy of the relatively weak and the relatively strong. The strong tend to legitimate themselves in law and attempt to prevent piracy of the weak. What counts as legitimate property and what as theft is a matter of metaphor, opinion and power.

At the moment, in information capitalism, corporations attempt to resolve the ambiguities around property by restricting the use of ideas and symbols through police, courts, fines, political pressure, implicit violence and imprisonment. They also seek to extend their property 'rights' even further into the realm of ideas, culture and self-expression, thus thieving more and more from culture generally. What was once partially common becomes limited. This 'piracy of the strong' generates social disruption, as sharing, copying and transformation are vital imaginative, creative and relationship-building processes. Culture and cultural 'advancement' cannot exist 
without them. As people and corporations need to communicate, borrow and 'steal' to make culture and property, so turning all information into property cuts people off from normal cultural and commercial production, and thus they have an incentive to rebel. Extension of property is theft, and manufactures theft. Manufacture of theft threatens more property, even though without some ownership of property the people thieving could not survive on their own artistic and cultural labour and productions. Thus the system is unstable.

In The Pirate Bay trial, the comments on the trial, and in the actions of the Piratpartiet we can see the playout of different types of power (political, national, legal, corporate) and the irresolvable metaphors which are used to justify theft and property, and the vagueness bordering those two categories. Metaphorically, there may be huge or no difference between $\mathrm{P} 2 \mathrm{P}$ and listening to a radio or a friend's CDs and then deciding what to buy. P2P can attack social fundamentals, while attacking P2P can also be an attack on social fundamentals. Attempting to suppress P2P can be an attempt by people who made money out of a technology, to halt a new technology of cultural exchange and production that threatens that ability, through institutions which express the power of those old relationships, or it can be an attempt to preserve order and allow cultural producers to survive. The questions of what is theft and what is property, revolve around the question of whether culture and ideas should be shared, rented or restricted.

It is, however, difficult to resist theft of any kind and rebellion is not easy. The piracy of the weak is enabled by the very mechanisms which attempt to distribute culture as property, and regulate theft by the weak. P2P occurs because of the network of relationships established by the information economy, and may not survive without them. As well, the social forms that develop around P2P are swarm-like, and gain little internal social or moral coherence and organisation. These movements also seem parasitic on a successful information property regime (ie one which supports producers, and provides the money which allows the swarm to live), so they undermine what they need to survive. Perhaps moving offline and forming organisations like the Piratpartiet allows the possibility of sustained impact.

French anarchists Comité Invisible have proposed that radical social restructuring could be generated via a web of self-organised experimental communes which would not 'occupy' the territory but become the territory, as '[e]very practice brings a territory into existence' (The Invisible Committee 2009: 108). Such a 
movement would abandon identity politics and pursue what we have implied is the variable visibility of the swarm; turning a socially-enforced anonymity to advantage, through 'conspiracy, nocturnal or faceless actions, creating an invulnerable position of attack' (113). This could be happening spontaneously in P2P activities, but there is no widespread revolutionary purity, and the problems with property, and P2P's dependence on information capitalism, cannot be resolved easily; they arise from the inevitable incoherencies generated by property and social life and upon which social life and property depend.

We live with uncertainty and mess, with no ultimate coherence, only struggle: only the paradox that property and theft are interconnected, and attempts to regulate property in the information society can undermine the very social functions of the property that allow it to operate. Attempts to give coherence are just comforting illusions whose failure becomes almost instantly apparent by the counter-measures which spring up.

At the moment capitalist information society is saved by the inertia of wealth and power, and the fact that not everything is information. The irreducible basics of water, food, power, shelter and clothing still have to be bought, grown or extracted from the earth - and this may become more precarious as environments degrade. On this parasitic basis, all other aspects of information property, both 'piratical' and 'legitimate', depend - and without recognising this dependence they can all face destruction.

\section{References}

[all web addresses available $30^{\text {th }}$ December 2011]

Alexa Internet (nd) 'About The Pirate Bay'. http://www.alexa.com/siteinfo/thepiratebay.org

Anderson, N. 2009, 'Reservella: The shadowy company behind The Pirate Bay', Ars Technica

http://arstechnica.com/tech-policy/news/2009/10/who-owns-the-pirate-bay-part-ii.ars

Anderson, N. 2010, 'How Wikileaks killed Spain's anti-P2P law', Ars Technica. 
http://arstechnica.com/tech-policy/news/2010/12/how-wikileaks-killed-spains-antip2p-law.ars

Anderson, N. 2012, "What we do is good": Pirate Bay lashes out as Swedish lawsuit finally ends', Ars Technica.

http://arstechnica.com/tech-policy/news/2012/02/what-we-do-is-good-pirate-baylashes-out-as-swedish-lawsuit-finally-ends.ars

Andersson, J. 2006 'The Pirate Bay and the ethos of sharing', in A. Hadzi et al. eds. Deptford.TV Diaries. London: Openmute Publishing. http://homepages.gold.ac.uk/jandersson/The_Pirate_Bay_and_the_ethos_of_sharing.pdf

Andersson, J. 2009. 'For the Good of the Net: The Pirate Bay as a Strategic Sovereign', Culture Machine, 10: 64-108.

Andersson, J. 2010, 'Peer-to-peer-based file-sharing beyond the dichotomy of 'downloading is theft' vs. 'information wants to be free': How Swedish file-sharers motivate their action', Goldsmiths, University of London, London.

Barnes, P. 2006. Capitalism 3.0: a Guide to Reclaiming the Commons. San Francisco: Berrett-Koehler.

Bauman, Z. 2007. Consuming Life. Oxford: Polity.

Ben-Atar, D. 2004. Trade Secrets: Intellectual piracy and the origins of American Industrial Power. Yale UP.

Berners-Lee, T. 1999. Weaving the Web: the Past, Present and Future of the World Wide Web by its Inventor. London: Orion.

Bourdieu, P. 1985. Distinction: A Social Critique of the Judgement of Taste. London: Routledge. 
Bridy, A. 2011. 'Is Online Copyright Enforcement Scalable?', Vanderbilt Journal of Entertainment \& Technology Law, Forthcoming.

http://ssrn.com/paper $=1739970$

Carrier, M.A. 2010, 'The Pirate Bay, Grokster, and Google', Journal of Intellectual Property Rights, vol. 17, pp. 7-17.

Chatterjee, P. 2003. 'Bechtel's Water Wars', CorpWatch May $1^{\text {st }}$. http://www.corpwatch.org/article.php?id=6670

Choate, P. 2005. Hot Property: the stealing of ideas in an age of globalization. NY: Alfred A Knopf.

Clastres, P. 1989. Society Against the State: Essays in Political Anthropology. NY: Zone.

Cox, J., Collins, A. \& Drinkwater, S. 2010, 'Seeders, leechers and social norms: Evidence from the market for illicit digital downloading', Information Economics and Policy, vol. 22, no. 4, Special Issue: Digital Piracy, December 2010, pp. 299-305.

Dahlberg, L. 2011. 'Pirates, Partisans, and Politico-Juridical Space', Law and Literature, 23(2): 262-281, 295.

Douglas, M. 1996. Thought Styles. Thousand Oaks: Sage.

enigmax 2009. 'Day 3 - The Pirate Bay’s 'King Kong' Defense'. Torrentfreak February 18.

http://torrentfreak.com/g-defense-090218/

enigmax 2011. 'Pirate Bay Founders “Should Be Denied” Supreme Court Hearing', TorrentFreak, october 26.

http://torrentfreak.com/pirate-bay-founders-should-be-denied-supreme-court-hearing111026 
ENS 2006. 'Bechtel Drops \$50 Million Claim to Settle Bolivian Water Dispute', Environmental News Service, January 19.

http://www.ens-newswire.com/ens/jan2006/2006-01-19-04.asp

Envisional 2011. Technical report: An Estimate of Infringing Use of the Internet, http://documents.envisional.com/docs/Envisional-Internet_Usage-Jan2011.pdf

ernesto 2011, 'I Know What You Downloaded on BitTorrent...', TorrentFreak, http://torrentfreak.com/i-know-what-you-downloaded-on-bittorrent-111210

Federici, S. 2004. Caliban and the Witch: Women, the Body and Primitive Accumulation. New York: Autonomedia.

Fleischer, R. \& Torsson, P. 2005. 'The Grey Commons - Strategic Considerations in the Copyfight', transcript of lecture given at $22 \mathrm{C} 3$ in Berlin, December.

http://web.archive.org/web/20090115214142/http://publication.nodel.org/The-GreyCommons

Girard, R. 1987. Things hidden since the foundation of the World. London: Athlone Press.

Geuss, M. 2012, 'Magnet links become the official currency of Pirate Bay', Ars Technica.

http://arstechnica.com/web/news/2012/02/what-torrent-pirate-bay-officially-makesmagnet-links-the.ars

Heller, M. 2008. Gridlock Economy: How too much ownership wrecks markets, stops innovation and costs lives. NY: Perseus.

Hinze, G. 2010. Not-So-Gentle Persuasion: US Bullies Spain into Proposed Website Blocking Law 17 December 2010 edn, Electronic Frontier Foundation http://www.eff.org/deeplinks/2010/12/not-so-gentle-persuasion-us-bullies-spainproposed 
Hume, D. 1888. Treatise of Human Nature. OUP.

iiNet, 2011. 'Encouraging legitimate use of Online Content: an iiNet view'.

http://www.iinet.net.au/press/releases/201103-encouraging-legitimate.pdf

Ingold, J 2009. 'Water bills back saving on rainy days'. The Denver Post 10 February. http://www.denverpost.com/news/ci_11667341

Jgela1 2005. 'Re: WHITE STRIPES / Pirate Bay - Torrents'.

http://static.thepiratebay.org/whitestripes_mail.txt

Kleiner, D. 2010. The Telekommunist Manifesto. Amsterdam: Institute of Network Cultures.

Knowledge Ecology International. 2011. 'The Anti-Counterfeiting Trade Agreement (ACTA)'.

http://keionline.org/acta

La Quadrature du Net. 2010. 'ACTA: Updated Analysis of the Final Version' http://www.laquadrature.net/en/acta-updated-analysis-of-the-final-version

Landes, D. 2009a. 'Showbiz lawyers push to have Pirates gagged'. TheLocal:

Sweden's News in English, $19^{\text {th }}$ May.

http://www.thelocal.se/19544/20090519/

Landes, D. 2009b. 'Showbiz reps appeal for more Pirate Bay loot'. TheLocal:

Sweden's News in English, 20 ${ }^{\text {th }}$ May

http://www.thelocal.se/19572/20090520

Lasar, M. 2011. 'Aussie ISPs to trial notifying suspected infringers of suspected misdeeds'. ArsTechnica, 28 November

http://arstechnica.com/tech-policy/news/2011/11/aussie-isps-to-trial-notifyingsuspected-infringers-of-suspected-misdeeds.ars 
Lazzarato, M. 1996. Immaterial Labor, trans. Colilli, P. \& Emory, E. http://www.generation-online.org/c/fcimmateriallabour3.htm

Lee, T.B. 2011, 'French copyright cops: we're swamped with "three strikes" complaints', Ars Technica.

http://arstechnica.com/tech-policy/news/2011/07/french-agency-were-swamped-withthree-strikes-complaints.ars

Lessig, L. 2005. Free Culture. Harmondsworth: Penguin.

Lewan, M. 2009. 'Sorting out the Pirate Bay verdict'. Cnet News, $21^{\text {st }}$ April. http://news.cnet.com/8301-1023_3-10224201-93.html

Linebaugh, P. \& Rediker, M. 2000. The Many-Headed Hydra: Sailors, Slaves, Commoners, and the Hidden History of the Revolutionary Atlantic. Boston: Beacon Press

Lobato, R. \& Thomas, J. 2011, 'The Business of Anti-Piracy: New Zones of Enterprise in the Copyright Wars', International Journal of Communication, Vol. 5, 2011.

McKenzie, G. \& Cochrane, G. 2009. 'Paul McCartney: Pirate Bay verdict 'fair', $B B C$ Newsbeat 20 April

http://news.bbc.co.uk/newsbeat/hi/music/newsid_8007000/8007950.stm

Mauss, M. 1997. The Gift; The Form and Reason for Exchange in Archaic Societies, Foreword by Mary Douglas. London: Routledge.

Miegel, F. \& Olsson, T. 2008, 'From pirates to politicians: The story of the Swedish file sharers who became a political party', in N. Carpentier, P. PruulmannVengerfeldt, K. Nordenstreng, M. Hartmann, P. Vihalemm, B. Cammaerts, H.

Nieminen \& T. Olsson (eds), Democracy, Journalism And Technology: New

Developments In An Enlarged Europe, Tartu University Press, Tartu.

http://www.researchingcommunication.eu/reco_book4.pdf. 
Mill, JS 1852. Principles of Political Economy with some of their Applications to Social Philosophy (Ashley ed.). Reprint 1987, Fairfield: Augustus M. Kelley.

Patton, R.H. 2008. Patriot Pirates: The Privateer War for Freedom and Fortune in the American Revolution. NY: Pantheon.

Piratpartiet nd. 'International - English - The Pirate Party'. http://www.piratpartiet.se/international/english

Proudhon, nd. What is Property, translated by Benjamin Tucker. London: William Reeves.

Riccardi, N. 2009. 'Who owns Colorado's rainwater?'. LATimes online March 18, 2009

http://articles.latimes.com/2009/mar/18/nation/na-contested-rainwater18

Sahlins, M. 1974. Stone Age Economics. London: Tavistock.

Schofield, J. 2009. 'Sweden's Pirate Party wins EU seat'. Guardian Technology Blog. http://www.guardian.co.uk/technology/blog/2009/jun/08/elections-pirate-partysweden

Smith, A. 1979. Wealth of Nations (Glasgow Edition). OUP.

Tehranian, J. 2007. 'Infringement Nation: Copyright Reform and the Law/Norm Gap', Utah Law Review, 2007(3): 537-550, http://ssrn.com/paper=1029151

TT 2009. 'ISPs refuse to shut down Pirate Bay'. TheLocal: Sweden's News in English, $18^{\text {th }}$ April. http://www.thelocal.se/18940/20090418/

The Invisible Committee 2009, The Coming Insurrection, Semiotext(e), Los Angeles. 
The Pirate Bay 2008. '25 Million’ Blog.

http://thepiratebay.org/blog/138

The Pirate Bay 2011a. 'Legal threats against The Pirate Bay'.

http://thepiratebay.org/legal

The Pirate Bay 2011b. 'The Pirate Bay'.

http://thepiratebay.org

The Pirate Bay 2012. 'New TPB investigation leaked'.

http://thepiratebay.se/blog/209

UPI 2009 'Pirate Bay sentences prompt protests'. UPI Entertainment News, $19^{\text {th }}$ April.

http://www.upi.com/Entertainment_News/2009/04/19/Pirate-Bay-sentences-promptprotests/UPI-15441240156999/

Wilk, RR \& Cligget, LC. 2007. Economies and Cultures: Foundations of Economic Anthropology. Westview. 